\title{
WIRAUSAHA MUDA MANDIRI: Learning, Sharing \& Practice
}

\author{
Wahyudi, Mukrodi, Hadyati Harras, \& Endang Sugiarti \\ Universitas Pamulang, Banten \\ dosen00560@unpam.ac.id
}
Submitted: $12^{\text {th }}$ Nov 2019/ Edited: $29^{\text {th }}$ December 2019/ Issued: 01 ${ }^{\text {st }}$ January 2020
Cited on: Wahyudi, Mukrodi, Hadyati Harras, \& Endang Sugiarti. (2020).
WIRAUSAHA MUDA MANDIRI: Learning, Sharing \& Practice. SCIENTIFIC
JOURNAL OF REFLECTION: Economic, Accounting, Management and Business, 3(1), 101-110.
DOI: $10.37481 /$ sjr.v3i1.120
https://doi.org/10.37481/sjr.v3i1.120

\begin{abstract}
There are two ways to survive, first work and second entrepreneurship. Choosing to be an entrepreneur is not easy, many things to learn, including yourself. Starting from building a business spirit, having knowledge, studying the market, creating products, and management. In this dedication opportunity, a qualitative method was chosen. Where all parties are directly involved in learning and practice. Activities carried out for 3 days, covered by studying theory, practice, and providing motivation. Where participants are encouraged to awaken the spirit of entrepreneurship by looking at the reality of business and business knowledge. The results of the activities provide conclusions; 1) to increase entrepreneurial activities in the community, the first thing it takes is building a business spirit, with routine business practice. 2) the role of tertiary institutions is mentoring by educating entrepreneurship. and 3) tertiary institutions bridge the community to get business assistance to the government.
\end{abstract}

\section{Keywords: Entrepreneurship, Learning, Sharing, Practice}

\section{PENDAHULUAN}

Di era digital segala sesuatu dibuat efisien, termasuk penggunaan tenaga kerja manusia. Dampaknya terjadi tingkat pengangguran yang tinggi, BPS mencatat lebih dari $30 \%$ angka pengangguran diakibatkan oleh sempitnya lapangan pekerjaan, terlebih angka pengangguran tertinggi paling banyak dari angkatan pendidikan sebesar $9 \%$. Kondisi ini, perlu disikapi oleh semua pihak khususnya masyarakat itu sendiri. Bagaimana dapat melihat berbagai tantangan dan batasan yang dimiliki agar dapat bertahan di tengah-tengah himpitan ekonomi. Perlu dicari cara dan solusi dalam menyelesaikannya, di antaranya membekali diri dengan pengetahuan berwirausaha. 
Aidis, et al (2008) mengemukakan, kemampuan berwirausaha semestinya dimiliki oleh setiap orang. Mengingat kegiatannya sangat erat dengan kehidupan sehari-hari, bahkan banyak orang yang lahir di lingkungan keluarga wirausaha. Dengan demikian, jika hal terburuk terjadi pada seseorang, misalnya gagal dalam pendidikan, ada hal yang bisa ia lakukan yakni menjadi pengusaha atau pedagang. Dengan demikian, tidak terjadi hal-hal buruk, justru dapat menurunkan angka pengangguran. Awogbenle \& Iwuamadi (2010), banyak pihak yang diperlukan terlibat agar lahir jiwa wirausaha, namun peran orang tua yang paling sentral. Sejauh mana mereka memiliki keinginan kuat untuk mendidik dan mengajarkan wirausaha sejak dini (Lee, et al2007; Arogundade, 2011; Tambunan, 2009).

Keunggulan Indonesia adalah demografi dan geografis yang besar, maka sudah pasti jumlah populasi menjadi keunggulan dalam memutuskan berwirausaha, terlebih di era digital segala sesuatunya telah terbuka dan mudah dijangkau. Maka dari pada itu, kesempatan besar tersebut harus dimanfaatkan dengan mengambil peran sebagai pelaku usaha. Namun, disadari menjadi pelaku usaha tidaklah semudah membalikkan telapak tangan.

Diperlukan sumber daya yang cukup termasuk kesiapan diri, pengetahuan, pengalaman dan biaya. Tujuan dilakukan Pengabdian ini adalah wujud dari pelaksanaan Tri Dharma Perguruan Tinggi, di mana setiap tenaga pengajar harus bermanfaat bagi lingkungan sekitarnya. Yang menjadi peserta PKM ini adalah masyarakat di Komplek Reni Jaya RT 9/14 dan mitra UMK Ayam Geprek dan UMK Pecel Pamulang.

Sebelum dilakukan suatu pengabdian, terlebih dahulu dilakukan suatu analisis situasi atau analisis lingkungan yang dapat memungkinkan para dosen dapat mengetahui tindakan apa yang paling tepat baik di dalam pelaksanaannya maupun di dalam menentukan strategi metode PKM. Dengan demikian, diharapkan terlaksana suatu pengabdian kepada masyarakat yang baik. Adapun metode pelaksanaan adalah berupa edukasi, sharing dan praktik usaha di lokasi Mitra UMK.

Metode tersebut diajukkan berdasarkan analisis situasi yang telah dilakukan, khususnya melihat karakteristik dari calon peserta. Bagaimana para peserta dapat antusias di dalam mengikuti kegiatan tersebut, yang mudah-mudahan dalam setiap kegiatannya memberikan nilai manfaat bagi kehidupan yang lebih baik di masa 
mendatang. Dari kegiatan ini akan dibuat suatu luaran berupa laporan dan jurnal ilmiah yang akan diterbitkan pada Januari 2020.

\section{LANDASAN TEORI}

Wirausaha merupakan kegiatan ekonomi yang membutuhkan jiwa, pengetahuan, kemampuan (keahlian), biaya, fasilitas, tenaga, waktu, dan semua hal yang diperlukan (Tambunan, 2007). Karena banyak hal yang dibutuhkan maka kegiatan wirausaha tidak bisa dipandang sederhana karena ruginya pasti, sementara kemungkinan berhasilnya tidak dapat ditentukan (Kuzilwa, 2005). Oleh karena itu hal yang diperlukan adalah melibatkan diri dalam berbagai kegiatan usaha, baik sendiri maupun mengikuti orang lain (keluarga, teman, atau tetangga) (Nkechi, et al., 2012).

Selain itu, belajar ilmu tentang wirausaha adalah langkah kedua. Ketika seseorang telah mendapatkan perasaan berdagang/ usaha, maka selanjutnya ia butuh ilmu pengetahuan tentang kewirausahaan. Yakni mempelajari konsep dasar wirausaha, manajerial, keuangan, strategi pemasaran, produksi, pelayanan dan lain sebagainya. Sehingga ketika mencoba berdagang/ usaha ia dapat mengatasi persaingan (Abimbola \& Agboola, 2011; Mathew, 2010; Thaddeus, 2012).

Tindak lanjut dari belajar adalah berlatih atau practice. Seyogianya, seorang pemula terlebih dahulu ikut belajar berdagang dengan orang lain. Di mulai dari yang ringan sampai dengan yang paling berat. Pelajar bagaimana cara mengatasi pelanggan, bagaimana merespons konsumen, bagaimana menyajikan, bagaimana mengenali karakteristik pelanggan, bagaimana memproduksi, kenali segmentasi pasar, tindakan apa yang diperlukan oleh seorang pedagang/ pengusaha. Dengan banyaknya latihan maka seseorang akan memiliki keyakinan dan fokus yang tinggi, sehingga jiwa yang telah diasah dan pengetahuan yang dimiliki akan dapat disinergikan dengan pengalaman, sehingga melahirkan suatu praktek usaha yang baik. Hussain et al (2014), praktek adalah langkah terakhir di dalam menguji jiwa wirausaha dan pengetahuan yang dimiliki. Sejauh mana jiwa usaha dapat berkembang sehingga dapat mengatasi masalah diri yang tidak berguna. Kemudian sejauh mana pengetahuan dapat efektif diterapkan, dengan keadaan yang kompleks, dengan pelanggan yang beragam, dengan persaingan yang ketat, dengan harga yang sulit dikendalikan, dengan material yang mahal dan susah, dan dengan faktor lain yang yang mengganggu berkembangnya usaha. 
Vol. 3, No. 1, January 2020

\section{METODE PENELITIAN}

\section{Metode}

Metode kegiatan ini berupa praktek wirausaha, yaitu dengan datang langsung ke tempat mitra usaha, namun dengan sedikit pembekalan pengetahuan dan konsep akademik. Sebagai suksesi dari kegiatan tersebut maka terlebih dahulu disusun perencanaan kegiatan, di antaranya:

1. Tahap Persiapan

Tahap persiapan yang dilakukan meliputi :

a. Menyusun konsep, program dan prosedur pelaksanaan

b. Menentukan lokasi dan peserta

c. Melakukan komunikasi dengan calon peserta, pendataan dan menyampaikan permohonan izin kepada pihak pejabat setempat.

d. Melakukan komunikasi dengan pihak mitra sebagai lokasi praktek.

e. Menyusun proposal PKM

2. Tahap Pelaksanaan Pelatihan

a. Mendatangi lokasi mitra usaha sesuai jadwal

b. Melakukan kegiatan sesuai dengan random acara

3. Metode Pelatihan

Melakukan praktek wirausaha dengan metode ceramah (penjelasan teoritis oleh dosen dengan waktu 15 menit), dialog interaktif (penjelasan pihak mitra dan tanya jawab), dan praktek (membuat suatu produk yang ada di mitra usaha).

\section{Proses Kegiatan}

Kegiatan pengabdian kepada masyarakat ini dilakukan dengan cara survey (tahap persiapan), pelatihan dan demonstrasi. Kegiatan ini dilaksanakan di Komplek Reni Jaya RT 009 / 014 Pondok Petir Pamulang, Tangerang Selatan. Kegiatan di mulai dengan melakukan survei lapangan untuk tahap penyusunan rencana kerja. Kegiatan survei ini dilakukan guna untuk mengidentifikasi permasalahan yang ada di RT 009 / 014 Reni Jaya yang dapat dicarikan solusinya dengan kegiatan masyarakat. Adapun tim dosen yang melakukan kegiatan survei ini adalah sebagai berikut :

1. Wahyudi

2. Endang Sugiarti 
Kegiatan survey tersebut menghasilkan kesepakatan hasil diskusi dengan tokoh masyarakat dan RT, yaitu:

1. Melakukan kegiatan wirausaha dengan melibatkan semua warga RT 009 / 014 Reni Jaya yang berminat mengikuti, khususnya remaja.

2. Melibatkan mitra usaha UMK dalam pelaksanaannya, khususnya UMK yang ada di sekitar RT 009 / 014 Reni Jaya.

Selanjutnya kegiatan pengabdian kepada masyarakat ini dijadwalkan akan dilaksanakan pada tanggal 01 November 2019 - 03 November 2019, di mana setiap dosen memiliki peran masing - masing.

1. Wahyudi dan Endang Sugiarti

Bertugas mengidentifikasi dan berkoordinasi baik dengan masyarakat RT 009 /

014 Reni Jaya maupun dengan mitra usaha, pengumpulan data-data yang dibutuhkan dalam pelaksanaan PKM. Proses ini dilakukan dengan diskusi langsung bersama dengan masyarakat dan mitra UMK guna memastikan kesiapan. Selain berperan di dalam tahap persiapan, peran utama yang dilakukan pada saat pelaksanaan adalah sebagai pemandu / moderator yang menyusun random acara serta memaparkan materi terkait dengan manajemen wirausaha.

2. Mukrodi

Bertugas menyusun proposal dan laporan Pengabdian Kepada Masyarakat, serta menyiapkan peralatan dan bahan - bahan yang dibutuhkan. Selain itu, dosen yang bersangkutan menjadi pemateri dalam memberikan motivasi berwirausaha. Target utamanya adalah menumubuh kembangkan semangat berwirausaha, yakni melalui pemutaran video dan menghadirkan contoh - contoh pengusaha sukses.

\section{Hadyati Harras}

Bertugas mengatur peserta dan mitra UMK pada saat pelaksanaan Pengabdian Kepada Masyarakat, termasuk menyusun anggaran yang dibutuhkan, serta menyiapkan bahan - bahan presentasi, pertanyaan, video visual, dan alat peraga lain yang dibutuhkan pada saat pelaksanaan Pengabdian Kepada Masyarakat. Selain itu, dosen yang bersangkutan berperan sebagai penyampai materi, khususnya di bidang manajemen keuangan. Pada bagiannya, dosen bersangkutan menjelaskan hal - hal apa saja yang diperlukan dalam menghitung, menyusun 
dan melaporkan seluruh kegiatan berupa laporan keuangan, sehingga diketahui apakah usaha yang sudah dilakukan telah balik modal atau belum, telah menguntungkan atau merugikan, memiliki peluang atau tidak dan lain sebagainya, dengan demikian memudahkan para pelaku usaha di dalam mengambil keputusan.

\section{HASIL PENELITIAN}

\section{Analisis Situasi}

\section{Demografi}

RT 009 / 014 berada di Jalan Raya Bratasena Reni Jaya Kel. Pondok Benda Pamulang, dengan batas - batas wilayah sebagai berikut:

a. Sebelah Utara berbatasan dengan RT 008 / 014

b. Sebelah Selatan berbatasan dengan Komplek Vila Pamulang

c. Sebelah Barat berbatasan dengan RT 010 / 014

d. Sebelah Timur berbatasan dengan RT 006 / 014

Letaknya yang strategis membuat wilayah tersebut cukup padat dengan berbagai aktivitas masyarakat, seperti pertokoan, usaha kecil menengah UMK, pendidikan, pasar, dan lain sebagainya. Dengan kelebihan tersebut, sangat tepat jika dilakukan pengembangan SDM pada masyarakat tersebut (RT 009 / 014 Reni Jaya), guna mengoptimalisasi potensi dan peluang yang dimiliki, serta berdampak pada kehidupan yang lebih baik.

\section{Kependudukan}

Masyarakat di lingkungan RT 009/014 berjumlah 40 KK dengan jumlah warga sebanyak 140 orang. Dengan banyaknya jumlah warga juga merupakan keunggulan tersendiri, di mana perlunya tata kelola kemasyarakatan yang baik. Misalnya dengan memasyarakatkan nilai - nilai agama dengan berbagai kegiatan ibadah (pengajian, maulid nabi, kurban, dan lain - lain), memasyarakatkan nilai nilai sosial dengan berbagai kegiatan warga (seperti kegiatan hari kemerdekaan, bersih - bersih lingkungan, dll), memasyarakatkan kemakmuran warga dengan berbagai kegiatan ekonomoi (seperti buka warung klontongan, jual nasi uduk, jual sate, jual soto, dan lain - lain), dan termasuk menyiapkan generasi mudah RT 009 / 014 Reni Jaya. 


\section{Profesi Warga}

Adapun karakteristik dari masyarakat tersebut kebanyakan orang tua laki-laki berprofesi sebagai karyawan swasta, sedangkan para ibu berprofesi sebagai ibu rumah tangga. Namun, keadaan saat ini sekitar $85 \%$ para orang tua telah pensiun dikarenakan usia sudah lanjut. Oleh karena itu, ada harapan dari para orang tua agar para anak muda yang ada di lingkungan RT 009/014 dapat menggunakan waktu dengan sebaik-baiknya dengan mengikuti berbagai kegiatan yang bermanfaat di masa depan, salah satunya mengikut pelatihan wirausaha.

\section{Permasalahan Mitra}

Adapun beberapa permasalahan yang tengah dihadapi masyarakat RT 009/014 Reni Jaya, khususnya generasi mudah adalah sebagai berikut:

a. Banyak membuang waktu dengan bermait HP / Gadget.

b. Sebagian anak mudah berprofesi sebagai ojek Online.

c. Sebagian anak mudah tidak bekerja.

\section{Pelaksanaan Kegiatan}

Berdasarkan informasi di atas, maka dapat dikemukakan suatu gagasan sederhana yakni berupa pelatihan kewirausahaan dengan tema: WIRAUSAHA MUDA MANDIRI: Learning, Sharing \& Practice. Dengan mengusung konsep wirausaha muda mandiri, maka program ini lebih memprioritaskan mendapatkan pengalaman langsung berwirausaha, maka dari pada itu agar gagasan tersebut dapat terlaksana dengan baik maka disuguhkan suatu konsep kemitraan dengan UMK Ayam Geprek dan UMK Pecel Pamulang.

Pelaksanaan pengabdian kepada masyarakat di daerah Reni Jaya RT 009/014 yang melibatkan peserta sebanyak 28 orang. Terdiri dari 7 anak-anak, 2 pelaku UMK, dan 19 masyarakat (anak muda dan orang tua). Pengabdian dilakukan selama 3 hari, di mulai dari hari Jumat 01 November 2019 - Minggu 03 November 2019. Selama pengabdian, perlakuan dilakukan dengan cara yang adaptif sesuai dengan usia.

a. Anak-anak

Perlakukan atau pendekatan yang dilakukan baik di hari pertama hingga hari ketiga adalah praktek. Di mana anak-anak langsung diajak praktek yang kemasannya adalah permainan. Mereka diberikan kebebasan untuk membuat 
ice chees dan ayam geprek sesuka mereka, yang penting mereka menikmati pelatihan. Cara ini dilakukan untuk memastikan anak-anak dapat menikmati pelatihan tanpa disadari, yakni melalui kemasan permainan. Namun, pada momen-momen tertentu disisipi istilah-istilah wirausaha, sehingga sisi edukasinya tetap ada. Misalnya sambil mereka membuat Ayam Geprek Keju Mozarela, mereka di ajarkan cara membuat adonan yang baik sambil memperkenalkan jenis atau nama adonan yang digunakan, sehingga materi tentang membuat produk berkualitas tersampaikan.

Dari hasil pengabdian tersebut, diketahui beberapa hal menarik tentang kewirausahaan pada anak-anak, di antaranya:

1) Anak-anak menikmati belajar usaha dengan cara yang mereka inginkan. Bahkan banyak hal yang anak-anak tidak sadari, sesungguhnya keingintahuannya telah mendorong sikap mereka untuk mau belajar apapun dengan catatan kemasan belajarnya adalah menyenangkan, baik menggunakan metode permainan, cerita, atau perlombaan.

2) Disadari, bahkan anak-anak lebih antusias di dalam belajar ketimbang orang dewasa. Ini menjadi kesempatan untuk memberikan pengetahuan dan pengalaman, sehingga sejak dini telah terbangun kebiasaan berdagang atau berwirausaha.

b. Dewasa

Cara atau metode pelatihan wirausaha kepada orang dewasa adalah $20 \%$ pengetahuan, 50\% praktek, dan 30\% diskusi (tanya jawab). Cara ini cukup ampuh mendorong para peserta untuk belajar usaha/ berdagang. Sebelum itu, hal yang perlu diketahui bahwa $80 \%$ peserta dewasa ini tidak memiliki latar belakang usaha/ dagang, sedangkan 5\% nya lahir di keluarga pedagang dan $15 \%$ adalah pensiunan. Dari hasil pelatihan diketahui beberapa hal, di antaranya:

1) Peserta pensiunan dan Peserta ibu rumah tangga

Semangat belajar sangat tinggi, namun banyak hal yang dikeluhkan, yakni terkait modal dan jenis usaha apa yang harus dilakoni. Mengingat, anggaran yang ada (hasil selama bekerja) tidak 
boleh hilang sia-sia, lebih baik digunakan untuk bertahan hidup. Terlebih sebagian besar telah mencoba usaha namun gagal.

Pada sesi pelatihan dijelaskan terkait hal yang mendasar dari berwirausaha atau menjadi pedagang, yakni memiliki jiwa dagang/ usaha. Artinya, solusi yang disampaikan adalah menjelaskan bagaimana peserta harus memiliki jiwa usaha. Di mana jiwa usaha itu pantang menyerah dengan kerugian atau keadaan buruk, mereka selalu usaha, mereka selalu mencari tahu hal-hal yang kurang berkenan, mereka meningkatkan kualitas produk dan pelayanan, dll. Jika menyerah, maka sesungguhnya kita tidak memiliki jiwa usaha, dan lebih baik dihentikan dagangnya, karena hanya akan membuang-buang modal.

2) Peserta dengan latar belakang pedagang

Peserta dengan latar belakang pedagang memiliki kekurangan dalam hal pengetahuan, khususnya tentang manajemen dan informasi. Mereka merasa jiwa usaha lebih baik, namun kesulitan mencari produk yang pas untuk konsumen, belum terlalu paham dengan konsep berjualan online, bingung mencari distributor yang menjual produk lebih murah, dll.

\section{KESIMPULAN}

Kegiatan pengabdian kepada masyarakat dengan tema WIRAUSAHA MUDA MANDIRI: Learning, Sharing \& Practice disambut baik oleh masyarakat. diketahui banyak kendala yang dihadapi, yang pertama terkait jiwa usaha. Disadari oleh banyak peserta bahwa mereka tidak memiliki karakter pedagang yang sabar menunggu konsumen, yang tidak mengeluh jika tidak ada yang beli, dll. Mereka menyadari menjadi usaha adalah bakat yang harus dipelajari sejak kecil.

Selain itu, pengetahuan dan modal menjadi kendala terbesar di dalam eksekusi usaha. Tanpa keduanya, masyarakat menyadari tidak akan pernah bisa usaha. Terlebih sulitnya mengajukan pinjaman bank membuat asa memudar. Ketidaktahuan masyarakat tentang cara berdagang yang benar membuat keraguan dan ketakutan muncul. Oleh karenanya masyarakat mengharapkan adanya pihak-pihak yang mampu membantu meningkatkan pengetahuan dan jaringan modal. 


\section{DAFTAR PUSTAKA}

Abimbola, O. H., \& Agboola, M. G. (2011). Environmental factors and entrepreneurship development in Nigeria. Journal of Sustainable Development in Africa, 13(4), 166-176.

Aidis, R., Estrin, S., \& Mickiewicz, T. (2008). Institutions and entrepreneurship development in Russia: A comparative perspective. Journal of Business Venturing, 23(6), 656-672.

Arogundade, B. B. (2011). Entrepreneurship education: An imperative for sustainable development in Nigeria. Journal of emerging trends in educational research and policy studies, 2(1), 26-29.

Awogbenle, A. C., \& Iwuamadi, K. C. (2010). Youth unemployment: Entrepreneurship development programme as an intervention mechanism. African Journal of Business Management, 4(6), 831-835.

Hussain, M. D., Bhuiyan, A. B., \& Bakar, R. (2014). Entrepreneurship development and poverty alleviation: An empirical review. Journal of Asian Scientific Research, $4(10), 558$.

Kuzilwa, J. A. (2005). The role of credit for small business success: A study of the National Entrepreneurship Development Fund in Tanzania. The Journal of Entrepreneurship, 14(2), 131-161.

Lee, S. H., Peng, M. W., \& Barney, J. B. (2007). Bankruptcy law and entrepreneurship development: A real options perspective. Academy of Management Review, 32(1), 257-272.

Mathew, V. (2010). Women entrepreneurship in Middle East: Understanding barriers and use of ICT for entrepreneurship development. International Entrepreneurship and Management Journal, 6(2), 163-181.

Nkechi, A., Emeh Ikechukwu, E. J., \& Okechukwu, U. F. (2012). Entrepreneurship development and employment generation in Nigeria: Problems and prospects. Universal Journal of Education and General Studies, 1(4), 88-102.

Tambunan, T. (2007). Entrepreneurship development: SMES in Indonesia. Journal of Developmental Entrepreneurship, 12(01), 95-118.

. (2009). Women entrepreneurship in Asian developing countries: Their development and main constraints. Journal of Development and Agricultural Economics, 1(2), 027-040.

Thaddeus, E. (2012). Perspectives: Entrepreneurship development \& growth of enterprises in Nigeria. Entrepreneurial practice review, 2(2), 31-35. 